Preprint of DOI: 10.1007/s10123-019-00107-y

\title{
Screening of gastrointestinal lipase inhibitors produced by microorganisms isolated from soil and lake sediments
}

Maria Angeles Camacho-Ruiz ${ }^{1,5}$, Enrique Ordaz ${ }^{1}$, Manuel R. Kirchmayr ${ }^{1}$, Hugo Esquivel ${ }^{2}$, Ali Assaf $^{4}$, Juan Carlos Mateos-Díaz ${ }^{1}$, Frédéric Carrière ${ }^{3}$ and Jorge A. Rodriguez ${ }^{1 *}$

${ }^{1}$ Biotecnología Industrial, Centro de Investigación y Asistencia en Tecnología y Diseño del Estado de Jalisco (CIATEJ), Zapopan, Jalisco, Mexico.

${ }^{2}$ Biotecnología Médica y farmacéutica, Centro de Investigación y Asistencia en Tecnología y Diseño del Estado de Jalisco (CIATEJ), Guadalajara, Jalisco, Mexico.

${ }^{3}$ CNRS, Aix Marseille Université, UMR 7282, Enzymologie Interfaciale et de Physiologie de la Lipolyse, Marseille, France.

${ }^{4}$ Centro de Investigación en Alimentación y Desarrollo, A.C., Hermosillo, Sonora, 83340, México.

${ }^{5}$ Departamento de Fundamentos del Conocimiento, Centro Universitario del Norte, Colotlán, Jalisco, Mexico.

${ }^{*}$ Correspondence to:

Jorge A. Rodriguez: Tel.: +52 (33) 33455200 ext. 2108; fax: ext. 1001. Email address: jrodriguez@ciatej.mx

Running Head: Screening of lipase inhibitors 
Abbreviations used:

$\beta$-CD, $\beta$-cyclodextrin; $\mathrm{BCG}$, bromocresol green; BSA, bovine serum albumin; BtA, butyric acid; Gly-SM, Glicerol-Soy milk agar media; NaTDC, sodium taurodeoxycholate; PHIBLA, pH indicator-based lipase assay; RGL, rabbit gastric lipase; rHPL, recombinant human pancreatic lipase; TG(4:0), tributyrin; THL, Tetrahydrolipstatin; YMD, yeast extract-malt extract-dextrose agar media. 


\section{Significance and impact of the study}

Only a few medications for obesity treatment are currently on the market. The inhibition of dietary

9

10 


\section{Abstract}

Gastrointestinal lipase inhibitors are molecules of pharmaceutical interest due to their use as antiobesity drugs. In this study, forty strains isolated from soil and sediments were identified with the ability to produce inhibition of gastrointestinal lipase activity. The biomass extract of these strains showed at least $50 \%$ inhibition in the hydrolysis of tributyrin by recombinant Human Pancreatic Lipase (rHPL) or Rabbit Gastric Lipase (RGL) by in vitro assays. Based on gene sequencing, the isolates were identified mainly as Streptomycetes. Moreover, none of the identified strains have been reported to be lipase inhibitor producers, so they can be viewed as potential sources for obtaining new drugs. $\mathrm{IC}_{50}$ values of the three best inhibitor extracts showed that AC104-10 was the most promising strain for production of gastrointestinal lipase inhibitors. AC104-10 shows 99\% homology (16S rRNA gene fragment) to Streptomyces cinereoruber strain NBRC 12756. An inhibitory study over trypsin activity revealed that AC104-10 extract, as well as THL, had no significant effect on the activity of this protease, showing its specificity for lipases.

Keywords: lipase inhibitor, Streptomyces, pancreatic lipase, gastric lipase. 


\section{Introduction}

Obesity is defined as "abnormal or excessive fat accumulation that presents a risk to health". The prevalence of obesity is increasing at an alarming rate and has become a worldwide public health problem. In 2014, more than 1.9 billion adults (18 years and older) were overweight, of whom over 600 million were obese (WHO 2016). Obesity is a significant risk factor for increased morbidity and mortality, especially for cardiovascular disease and diabetes. It also increases the risk of cancer and chronic diseases, including osteoarthritis, liver and kidney disease, sleep apnea, and depression. Despite the substantial adverse effects of obesity, weight loss can result in a significant risk reduction for the majority of these comorbid conditions (Pi-Sunyer 2009).

Obesity is primarily regarded as a disorder of lipid metabolism and the enzymes involved in this process could be selectively targeted to develop anti-obesity drugs. The lipolysis of triglycerides from dietary lipid intake is due principally to gastrointestinal lipases. During whole lipid digestion, human gastric lipase (HGL) and human pancreatic lipase (HPL) contribute to hydrolyze $17.5 \%$ and $48.5 \%$ of the meal TG acyl chains, respectively (Carriere et al. 1993). When an optimal lipolysis occurs, triglycerides are transformed into a 2-monoglyceride (2-MG) and two free fatty acids (FFA). These are absorbed by the enterocytes to synthesize new triglyceride molecules, which are transported to different organs through lipoproteins (chylomicrons) after a meal (Phan and Tso 2001).

For almost two decades, a successful pharmacological treatment of obesity has involved the inhibition of dietary triglyceride absorption via inhibition of gastrointestinal lipases. A number of inhibitors of pancreatic lipase have been described from natural sources. Alkaloids, carotenoids, glycosides, polyphenols, polysaccharides, saponins and terpenoids are well studied, and lipophilic compounds from microbial sources are the most active (Lunagariya et al. 2014).

However, of all reported inhibitors, the only clinically approved pancreatic lipase inhibitor is Orlistat $\left(\mathrm{Xenical}^{\mathrm{TM}}, \mathrm{Alli}^{\mathrm{TM}}\right)$. The active compound in Orlistat is tetrahydrolipstatin (THL), a hydrogenated derivative of lipstatin, which is a $\beta$-lactone produced by Streptomyces toxytricini (Weibel et al. 1987). 
THL inhibits pancreatic and gastric lipases from several species, including human, with comparable efficiency, and has been shown to be an effective tool for the treatment of human obesity lipases (Carrière et al. 2001). Nevertheless, Orlistat has been associated with cases of hepatotoxicity (Lau and Chan 2002; Kose el. al 2015). So far, a cause and effect relationship of severe liver injury with Orlistat use has not been established. Nevertheless, FDA has added information about reported cases of severe liver injury on the label of Xenical ${ }^{\mathrm{TM}}$ and Alli ${ }^{\mathrm{TM}}$ (FDA 2009).

The success of Orlistat has led to the search and identification of new gastrointestinal lipase inhibitors showing no such adverse reactions. To accomplish the search, a sensitive and reliable high throughput screening (HTS) assay that takes into account the conditions in which gastrointestinal lipases act should be devised. The use of a triglyceride (a natural substrate for these enzymes) is suitable for the HTS lipase inhibition assay. HTS methods to detect pancreatic lipase inhibition using triglycerides have been developed, including ultraviolet (UV) spectrophotometric assays to detect lipase activity using triglycerides from Aleurites fordii seeds oil (tung oil) (Mendoza et al. 2012;Serveau-Avesque et al. 2013) and Punica granatum seed oil (Pomegranate oil) (Ulker et al. 2016). However, these methods cannot be usable at acid $\mathrm{pH}$ for detection of gastric lipase inhibition. A new spectrophotometric method called PHIBLA (pH Indicator Based Lipase Assay) was reported to carry out assays in a broad $\mathrm{pH}$ range in the presence of detergents such as bile salts (Camacho-Ruiz et al. 2015). This HTS method is suitable to measure the inhibition of human pancreatic lipase (HPL) and human gastric lipase or homologue lipases with many similarities such as porcine pancreatic lipase (PPL) (de Caro et al. 1981) and rabbit gastric lipase (RGL) (Roussel et al. 1999), close to in vivo conditions in order to find specific inhibitors for these kinds of lipases.

The aim of this work was to screen for potential new and specific inhibitors of gastrointestinal lipases such as rHPL an RGL, from a collection of microorganisms isolated from unexplored Mexican ecosystems: sediments of Chapala Lake, and soil samples from uncultivated land on the lakeshore and in the Sonoran Desert. 


\section{Results and discussion}

\section{Isolation of microorganisms and screening of gastrointestinal lipase inhibitors}

Microorganisms are found in all sorts of natural environments where their growth is affected both by interactions with other populations (synergistic, antagonistic, etc.) and by the physical and chemical characteristics of such environments. Because of these interactions, secondary metabolites are produced with various biological activities which play an important role in their survival. For this reason, the microorganisms explored in this work were isolated from both an extreme environment, such as the Sonoran Desert, and a mesophilic environment, such as Chapala Lake (lakeshore soil and sediments).

One hundred sixty-six strains were isolated and incubated for a week on Petri dishes containing yeast malt dextrose agar media (YMD) or Glycerol-Soy milk agar media (Gly-SM) for biomass and subsequent secondary metabolite production. It is noteworthy that solid agar media is recommended for exploration of chemical diversity because agar plug samples are easily analyzed for optimal representation of the qualitative secondary metabolome (Frisvad 2012). In addition, when surface cultures are made, the biomass can be easily separated from the culture medium by scraping with a spatula.

An acetone extraction was performed to the obtained biomass and subsequently fractionated with hexane. Extracts were evaporated under vacuum and suspended in DMSO at a final concentration of 50 $\mathrm{mg} \mathrm{ml}^{-1}$ for inhibition test.

Extracts obtained from strains cultured in GLY-SM medium had a greater inhibitory effect on the activity of gastrointestinal lipases than those obtained from cultures in YMD media (data not shown). These results were expected since culture media formulated with soy products has been widely used for the production of secondary metabolites with Streptomycetes, including pancreatic lipase inhibitors, with satisfactory results (Luthra and Dubey 2012).

Extract samples from 40 strains showed an inhibitory effect of more than $50 \%$ for one or both gastrointestinal lipases tested. Out of these 40 strains, 21 were isolated from lakeshore soil, 8 from lake 
sediment and 11 from desert soil. It should be noted that the extracts that had the greatest inhibitory effect in both lipases were obtained from cultures of strains isolated from lakeshore soil samples. These results agree with those obtained by Kilaru (2005), who observed more strains producing lipase inhibitors isolated from lakes than strains isolated from desert soils.

Residual lipase activity of rHPL and RGL on tributyrin (TG(4:0)) after addition of $1 \mu \mathrm{L}$ (50 $\mu \mathrm{g}$ ) of extract samples are shown in Fig. 1. Complete inhibition of lipase activity was observed for AC104-10 and AC104-6 extract samples, both isolated form lakeshore soil samples taken at 10-20 cm depth. Additionally, extract from AC3-4 strain caused a significant inhibitory effect for both lipases, obtaining a residual activity of $20 \%$ for rHPL and $35 \%$ for RGL. This strain was isolated from a lakeshore soil sample taken at $<10 \mathrm{~cm}$ depth. Photographs of GLY-SM agar cultures of the three strains that showed the higher inhibitory effect in both rHPL and RGL are shown in Fig. 2. It can be seen that the three strains have different morphologies, suggesting that they are strains of different genus, species or variety.

\section{Identification of isolated strains producing lipase inhibitors}

Strains whose extracts showed an inhibitory effect greater than $50 \%$ on any tested lipase were identified by sequencing the $16 \mathrm{~S}$ ribosomal RNA gene or ITS region. The results showed that 27 of the identified bacteria belong to the order of Actinomycetales, of which 24 belong to the genus Streptomyces. Moreover, 4 filamentous fungi and 3 Bacillales were also identified (Table 1). These results were expected because Streptomycetes have been the major source of microbial lipase inhibitors for decades (Lunagariya et al. 2014). However, none of the identified strains had been reported as lipase inhibitor producers.

The strains that showed the greatest potential as producers of lipase inhibitors were: AC104-10 with a 99\% homology with Streptomyces cinereoruber strain NBRC 12756; AC3-4 with a 99\% homology with Nocardia yamanashiensis strain IFM 0265; and AC104-6, which was not possible to identify. 
The phylogenetic distribution of the isolates that produced lipase inhibitors, and reported lipase inhibitor producing bacteria were analyzed by the neighbor-joining method (Fig. 3). Interestingly, AC104-10 strain is in the same cluster as Streptomyces albolongus, a valilactone producing bacterium. Valilactone, a $\beta$ lactone, was reported as a potent lipase and esterase inhibitor, with an $\mathrm{IC}_{50}$ of $0.00014 \mu \mathrm{g} \cdot \mathrm{ml}^{-1}$ over hog pancreas lipase, and $0.029 \mu \mathrm{g} \cdot \mathrm{ml}^{-1}$ over hog liver esterase (Kitahara et al. 1987).

\section{Lipase inhibition effectiveness of the microbial extracts}

$\mathrm{IC}_{50}$ values of biomass extracts for pancreatic and gastric lipase inhibition were determined. The results in Fig. 4 show the dose-response curves of AC104-10, AC104-6 and AC3-4 extracts on rHPL and RGL inhibition. All extracts markedly inhibited pancreatic and gastric lipase activity in dose-dependent relationships. The findings showed that AC104-10 extract was the most effective lipase inhibitor with $\mathrm{IC}_{50}$ values of $12.16 \mathrm{mg}$ of extract $\cdot \mathrm{mg}^{-1}\left(0.0058 \mathrm{mg} \cdot \mathrm{ml}^{-1}\right)$ of $\mathrm{rHPL}$ and $7.63 \mathrm{mg} \cdot \mathrm{mg}^{-1}\left(0.03 \mathrm{mg} \cdot \mathrm{ml}^{-1}\right)$ of RGL, followed by AC104-6 extract with $\mathrm{IC}_{50}$ values of $170.66 \mathrm{mg} \cdot \mathrm{mg}^{-1}\left(0.08 \mathrm{mg} \cdot \mathrm{ml}^{-1}\right)$ of $\mathrm{rHPL}$ and $10.08 \mathrm{mg} \cdot \mathrm{mg}^{-1}\left(0.04 \mathrm{mg} \cdot \mathrm{ml}^{-1}\right)$ of RGL. AC3-4 extract was the least potent inhibitor among the extracts tested with $\mathrm{IC}_{50}$ values of $421.28 \mathrm{mg} \cdot \mathrm{mg}^{-1}\left(0.2 \mathrm{mg} \cdot \mathrm{ml}^{-1}\right)$ of $\mathrm{rHPL}$ and $205.53 \mathrm{mg} \cdot \mathrm{mg}^{-1}\left(0.82 \mathrm{mg} \cdot \mathrm{ml}^{-1}\right)$ of RGL. However, all extracts were less potent than THL (control) in inhibiting gastrointestinal lipases. THL $\mathrm{IC}_{50}$ values obtained were $0.0071 \mathrm{mg} \cdot \mathrm{mg}^{-1}\left(3.41 \times 10^{-6} \mathrm{mg} \cdot \mathrm{ml}^{-1}\right)$ of $\mathrm{rHPL}$ and $0.0013 \mathrm{mg} \cdot \mathrm{mg}^{-1}$ $\left(5.2 \times 10^{-6} \mathrm{mg} \cdot \mathrm{ml}^{-1}\right)$ of RGL. There is a remarkable difference between the extracts tested and THL, which is attributed to THL being a pure molecule. We cannot ensure that the inhibitor molecules present in these extracts will be more potent than THL once purified. However, a significant difference of $\mathrm{rHPL} / \mathrm{RGL} \mathrm{IC}_{50}$ inhibition ratio was found for the best extracts tested in comparison with THL where values above 1 mean greater inhibition of rHPL. For THL, an $\mathrm{IC}_{50}$ inhibition ratio rHPL/RGL of 5.46 was obtained, whereas for the AC104-10, AC3-4 and AC104-6 extracts, $\mathrm{IC}_{50}$ inhibition ratios rHPL/RGL of 1.59, 2.04 and 16.93 were determinate, respectively. These results suggest that the extract AC104-6 shows a higher inhibition for rHPL in comparison with RGL (as shown by THL), three times greater than THL, whereas the AC3-4 
and AC104-10 extracts had a similar inhibition for both rHPL and RGL, with AC104-10 being the most 151 effective extract $\left(\mathrm{IC}_{50}\right)$ for lipase inhibition.

A separate study in which the effects of AC104-10 extract and THL were measured over trypsin

153 activity from porcine pancreas was carried out using BAPNA ( $N \alpha$-Benzoyl-L-arginine 4-nitroanilide hydrochloride) as substrate. Neither AC104-10 extract nor THL had any effect over trypsin activity (data 155 not shown) suggesting that the lipase inhibitor produced by AC104-10 strain is as specific for lipases as 156 THL

157 


\section{Materials and methods}

159

160

161

162

163

164

165

166

167

168

169

170

171

172

173

174

175

176

177

178

179

\section{Chemicals}

Tributyrin (TG(4:0)), butyric acid (BtA), $\mathrm{BSA}, \mathrm{NaCl}, \mathrm{CaCl}_{2}$, sodium taurodeoxycholate (NaTDC), $\beta$-cyclodextrin ( $\beta$-CD), bromocresol green (BCG), p-nitrophenol, malic acid, MOPS, 2-Methyl-2propanol (tert-Butanol), DMSO, Tetrahydrolipstatin (THL), and Butylated hydroxytoluene (BHT) were purchased from Sigma-Aldrich..

\section{Enzymes}

Recombinant human pancreatic lipase (rHPL) was expressed in Pichia pastoris and purified from culture media as described by Belle et al. (2007). Porcine colipase was partly purified from lipid-free pancreatic powder using the procedure described in Fernandez et al. (2007). Rabbit gastric lipase (RGL) was purified according to Moreau et al. (1988).

\section{Isolation and identification of microorganisms}

Soil samples were collected from uncultivable land on the lakeshore (Las Tortugas, Jalisco, Mexico; latitude $20^{\circ} 18^{\prime} 34^{\prime \prime} \mathrm{N}$, longitude $102^{\circ} 49^{\prime} 19^{\prime \prime} \mathrm{W}$, altitude $1562 \mathrm{~m}$ ), from the Sonoran Desert (Sonora, Mexico; latitude $28^{\circ} 48^{\prime} 10^{\prime \prime} \mathrm{N}$, longitude $111^{\circ} 12^{\prime} 13^{\prime \prime} \mathrm{W}$, altitude $115 \mathrm{~m}$ ) and from sediment of Chapala Lake (Jalisco and Michoacán, Mexico) where the following four sites were selected: San Juan Cosala (latitude $20^{\circ} 16^{\prime} 51^{\prime \prime} \mathrm{N}$, longitude $103^{\circ} 20^{\prime} 20^{\prime \prime} \mathrm{W}$, altitude $1519 \mathrm{~m}$ ), San Luis Soyatlan (latitude $20^{\circ} 12^{\prime} 8^{\prime \prime} \mathrm{N}$, longitude $103^{\circ} 18^{\prime} 11^{\prime \prime} \mathrm{W}$, altitude $1522 \mathrm{~m}$ ), Tuxcueca (latitude $20^{\circ} 9^{\prime} 19^{\prime \prime} \mathrm{N}$, longitude $103^{\circ} 10^{\prime} 37^{\prime \prime} \mathrm{W}$, altitude $1521 \mathrm{~m}$ ) and Cojumatlan (latitude $20^{\circ} 7^{\prime} 24{ }^{\prime \prime} \mathrm{N}$, longitude $102^{\circ} 50^{\prime} 18^{\prime \prime} \mathrm{W}$, altitude $1522 \mathrm{~m})$. At the lakeshore, two soil samples were collected at each spot, one on the surface layer, and the 
other at a depth of about 10 to $20 \mathrm{~cm}$. Isolation of strains was carried out using the procedure described in Kuster and Williams (1964).

For molecular identification, pure liquid cultures were used for total DNA extraction with Dneasy® Plant Mini Kit (Qiagen, Hilden, Germany). PCR reactions were carried on a Veriti ${ }^{\mathrm{TM}}$ 96-well thermal cycler (Applied Biosystems, Foster City, USA) using OneTaq Hot Start DNA Polymerase (New England Biolabs). Ribosomal 16S fragment of approximately 1,300 bp was amplified by PCR with primers $63 \mathrm{~F}$ and 1387R (Marchesi et al. 1998) for actinomycetes identification, and approximately 600 bp fragment from the internal transcribed spacer (ITS) region in the nuclear ribosomal repeat unit was amplified by PCR with primers ITS1 and ITS4 (Gardes and Bruns 1993) for filamentous fungi identification. PCR products were sent to Macrogen USA Corp. for sequencing. Consensus sequences were obtained with CLC Main Workbench 5.5 software package (CLCBio, Aarhus, Denmark) and identification was done using the BLASTn algorithm from GenBank database comparing to recorded sequences.

\section{Biomass production and organic solvent extraction of inhibitors}

Isolated microorganisms were cultured on $60 \times 15 \mathrm{~mm}$ Petri dishes on two different media. The YMD media contained $4 \mathrm{~g} \mathrm{l}^{-1}$ yeast extract, $10 \mathrm{~g} \mathrm{l}^{-1}$ malt extract, $4 \mathrm{~g} \mathrm{l}^{-1}$ dextrose and $18 \mathrm{~g} \mathrm{l}^{-1}$ bacteriological agar ( $\mathrm{pH}$ 7.0). Moreover, the soy milk-glycerol media was composed of $60 \%$ lipid free natural soy milk $\left(\mathrm{ADES}^{\circledR}\right)$ and $2 \%$ glycerol. Cultures were incubated at $30{ }^{\circ} \mathrm{C}$ for 7 days. After that, biomass was carefully collected in a $2 \mathrm{ml}$ micro tube from the agar surface by scraping with a spatula. The biomass was stored at $-20{ }^{\circ} \mathrm{C}$ until use.

Extractions from biomass were performed with acetone (containing $0.1 \%$ of BHT) in a ratio of 2 $\mathrm{ml}$ of solvent per $\mathrm{g}$ of biomass for one hour at room temperature with sonication at 6 intervals of $10 \mathrm{~min}$, using an ultrasonic cell disruptor $\left(\right.$ SONICS $^{\circledR}$ Vibro-Cell $\left.^{\circledR}\right)$. Biomass was then separated by centrifugation at $9402 \mathrm{~g}$. Supernatants were collected in new $2 \mathrm{ml}$ micro tubes and one volume of hexane was added to each one. Samples were mixed vigorously in a vortex mixer and centrifuged at $9402 \mathrm{~g}$. The upper phase 
was collected in new $1.5 \mathrm{ml}$ micro tubes and dehydrated with anhydrous ammonium sulfate. After filtration, extracts were evaporated in vacuum, dissolved in DMSO (at final concentration of $50 \mathrm{mg} \mathrm{ml}^{-1}$ ) and used to measure the lipase inhibitory effect.

\section{Lipase inhibition assay}

The enzyme-inhibitor pre-incubation method was used (Ransac et al. 1997), in aqueous medium and the absence of substrate, to test for direct interactions that might occur between the lipase and the inhibitor. For the lipase inhibition assay, $1 \mu \mathrm{l}$ of extracts (50 $\mathrm{mg} \mathrm{ml}^{-1}$ in DMSO) was pre-incubated in a 96 well microplate with $20 \mu$ of rHPL ( $0.48 \mathrm{ng} \mathrm{l}^{-1}$ in $2.5 \mathrm{mmol} \mathrm{l}^{-1}$ MOPS buffer, $\mathrm{pH}$ 7.2) or RGL (4 $\mathrm{ng} \mu \mathrm{l}^{-1}$ in $1.5 \mathrm{mmol}^{-1}$ malate buffer, $\mathrm{pH}$ 5.0) in the presence of 4 mmol $\mathrm{l}^{-1}$ NaTDC. Residual enzyme activity was measured after $1 \mathrm{~h}$ of continuous shaking $(6000 \mathrm{~g})$ pre-incubation at room temperature. THL was used as positive control at an enzyme:inhibitor molar ratio of 1:100, and $1 \mu 1$ of DMSO was used as a negative control. Residual activity was expressed as the percentage of activity retained in the sample relative to the negative control inhibition.

\section{Lipase activity assay}

Lipase activity was determined using the $\mathrm{pH}$ indicator based lipase assay (PHIBLA) (CamachoRuiz et al. 2015) by indirect measurement of the release of butyric acid upon hydrolysis of tributyrin (TG(4:0)). For rHPL activity assays, the substrate emulsion was prepared as follows: $0.5 \mathrm{ml}$ of $\rho$ nitrophenol stock solution (10 $\mathrm{mmol}^{-1}$ in tert-butanol) was dissolved in $9 \mathrm{ml}$ of $2.5 \mathrm{mmol} \mathrm{l}^{-1}$ MOPS (pH 7.2) buffer solution containing $150 \mathrm{mmol} \mathrm{l}^{-1} \mathrm{NaCl}, 1 \mathrm{mM} \mathrm{CaCl}{ }_{2}, 3 \mathrm{mg} \cdot \mathrm{ml}^{-1} \beta-\mathrm{CD}, 0.5 \mathrm{mmol} \mathrm{l}^{-1} \mathrm{NaTDC}$ and colipase (in a five molar excess), then $0.5 \mathrm{ml}$ of tributyrin stock solution $\left(100 \mathrm{mmol} \mathrm{l}^{-1}\right.$ in tertbutanol) was immediately added drop by drop in a continuous vigorous vortexing. For RGL activity assays, the substrate emulsion was prepared similarly: $0.5 \mathrm{ml}$ of bromocresol green stock solution (5 
mmol $\mathrm{l}^{-1}$ in tert-butanol) was dissolved in $9 \mathrm{ml}$ of $1.5 \mathrm{mmol} \mathrm{l}^{-1}$ malate (pH 5.0) buffer solution containing $150 \mathrm{mmol} \mathrm{l}^{-1} \mathrm{NaCl}, 1.5 \mu \mathrm{mol} \mathrm{l}^{-1} \mathrm{BSA}, 3 \mathrm{mg} \mathrm{ml}^{-1} \beta-\mathrm{CD}$ and $2 \mathrm{mmol}^{-1} \mathrm{NaTDC}$, then $0.5 \mathrm{ml}$ of tributyrin stock solution (100 $\mathrm{mmol} \mathrm{l}^{-1}$ in tert-butanol) was immediately added drop by drop with continuous vigorous vortexing. Substrate emulsions were prepared at the time of the test.

To each well of a microplate containing $20 \mu$ l of enzyme substrate, $100 \mu$ of corresponding substrate emulsion were added. Subsequently, the plate was positioned in a microtiter plate scanning spectrophotometer (x-Mark ${ }^{\mathrm{TM}}$, Bio-Rad) and shaken for $5 \mathrm{~s}$ before each reading. The decrease in absorbance was recorded every $30 \mathrm{~s}$ at $410 \mathrm{~nm}$ for rHPL assays and $610 \mathrm{~nm}$ for RGL assays. Activity assays were performed at $37^{\circ} \mathrm{C}$. Blanks without enzyme were carried out, and data were collected at least in triplicate for $15 \mathrm{~min}$. 
240 The authors thank Brian Walsh from Peace Corps for revising the English manuscript. 


\section{References}

242 Belle, V., Fournel, A., Woudstra, M., Ranaldi, S., Prieri, F., Thome, V., Currault, J., Verger, R., 243 Guigliarelli, B. and Carriere, F. (2007) Probing the opening of the pancreatic lipase lid using site-directed 244 spin labeling and EPR spectroscopy. Biochem 46, 2205-2214.

245 Camacho-Ruiz, M.A., Mateos-Diaz, J.C., Carriere, F. and Rodriguez, J.A. (2015) A broad pH range indicator-based spectrophotometric assay for true lipases using tributyrin and tricaprylin. J Lipid Res 56,

247 1057-1067.

Carrière, F., Renou, C., Ransac, S., Lopez, V., De Caro, J., Ferrato, F., De Caro, A., Fleury, A., SanwaldDucray, P., Lengsfeld, H., Beglinder, C., Hadvary, P., Verger, R. and Laugier, R. (2001) Inhibition of gastrointestinal lipolysis by Orlistat during digestion of test meals in healthy volunteers. Am J Physiol Gastrointest Liver Physiol 281, G16-G28.

de Caro, A., Bonicel, J., Pieroni, G. and Guy, O. (1981) Comparative studies of human and porcine pancreatic lipases : N-terminal sequences, sulfhydryl groups and interfacial activity. Biochimie 63, 799801.

FDA (2009) Early Communication about an Ongoing Safety Review Orlistat (marketed as Alli and Xenical). In Drugs. Silver Spring. U.S.

Fernandez, S., Jannin, V., Rodier, J.-D., Ritter, N., Mahler, B. and Carrière, F. (2007) Comparative study on digestive lipase activities on the self emulsifying excipient Labrasol@, medium chain glycerides and PEG esters. Biochim Biophys Acta, Mol Cell Biol Lipids 1771, 633-640.

Frisvad, J.C. (2012) Media and growth conditions for induction of secondary metabolite production. Methods Mol Biol (Clifton, NJ) 944, 47-58.

Gardes, M. and Bruns, T.D. (1993) ITS primers with enhanced specificity for basidiomycetes--application to the identification of mycorrhizae and rusts. Mol Ecol 2, 113-118. 
Kilaru, N.B. (2005) Production of a novel lipase inhibitor from Streptomyces sp. In Department of Fermentation Technology and Bioengineering, Central Food Technological Research Institute. Mysore, India: University of Mysore.

Kitahara, M., Asano, M., Naganawa, H., Maeda, K., Hamada, M., Aoyagi, T., Umezawa, H., Iitaka, Y. and Nakamura, H. (1987) Valilactone, an inhibitor of esterase, produced by actinomycetes. J Antibiot 40, 1647-1650.

Kose, M., Emet, S., Akpınar, T.S., Ilhan, M., Gok, A.F.K., Dadashov, M. and Tukek, T. (2015) An Unexpected Result of Obesity Treatment: Orlistat-Related Acute Pancreatitis. Case Rep Gastroenterol 9, 152-155.

Kuster, E. and Williams, S.T. (1964) Selection of Media for Isolation of Streptomycetes. Nature 202, 928-929.

Lau, G. and Chan, C.L. (2002) Massive hepatocellular [correction of hepatocullular] necrosis: was it caused by Orlistat? Med Sci Law 42, 309-312.

Lunagariya, N.A., Patel, N.K., Jagtap, S.C. and Bhutani, K.K. (2014) Inhibitors of pancreatic lipase: state of the art and clinical perspectives. EXCLI J 13, 897-921.

Luthra, U. and Dubey, R.C. (2012) Medium optimization of lipstatin from Streptomyces toxytricini ATCC 19813 by shake flask study. Int J Microbiol Res 4, 266-269.

Marchesi, J.R., Sato, T., Weightman, A.J., Martin, T.A., Fry, J.C., Hiom, S.J. and Wade, W.G. (1998) Design and Evaluation of Useful Bacterium-Specific PCR Primers That Amplify Genes Coding for Bacterial 16S rRNA. Appl Environ Microbiol 64, 795-799.

Mendoza, L.D., Rodriguez, J.A., Leclaire, J., Buono, G., Fotiadu, F., Carriere, F. and Abousalham, A. (2012) An ultraviolet spectrophotometric assay for the screening of sn-2-specific lipases using 1,3-Odioleoyl-2-O-alpha-eleostearoyl-sn-glycerol as substrate. J Lipid Res 53, 185-194.

Moreau, H., Gargouri, Y., Lecat, D., Junien, J.-L. and Verger, R. (1988) Purification, characterization and kinetic properties of the rabbit gastric lipase. Biochim Biophys Acta 960, 286-293.

Phan, C.T. and Tso, P. (2001) Intestinal lipid absorption and transport. In Front Biosci. pp.299-319. 
Pi-Sunyer, X. (2009) The Medical Risks of Obesity. Postgrad Med 121, 21-33.

291 Ransac, S., Gargouri, Y., Marguet, F., Buono, G., Beglinger, C., Hildebrand, P., Lengsfeld, H., Hadvary, P. and Verger, R. (1997) Covalent inactivation of lipases. Methods Enzymol 286, 190-231. Roussel, A., Canaan, S., Egloff, M., Riviere, M., Dupuis, L., Verger, R. and Cambillau, C. (1999) Crystal structure of human gastric lipase and model of lysosomal acid lipase, two lipolytic enzymes of medical interest. J Biol Chem 274, 16995-17002.

Serveau-Avesque, C., Verger, R., Rodriguez, J.A. and Abousalham, A. (2013) Development of a highthroughput assay for measuring lipase activity using natural triacylglycerols coated on microtiter plates. Analyst 138, 5230-5238.

Ulker, S., Placidi, C., Point, V., Gadenne, B., Serveau-Avesque, C., Canaan, S., Carriere, F. and Cavalier, J.F. (2016) New lipase assay using Pomegranate oil coating in microtiter plates. Biochimie 120, 110-118. Weibel, E.K., Hadvary, P., Hochuli, E., Kupfer, E. and Lengsfeld, H. (1987) Lipstatin, an inhibitor of pancreatic lipase, produced by Streptomyces toxytricini. I. Producing organism, fermentation, isolation and biological activity. $J$ Antibiot 40, 1081-1085. 
Figure legends:

307 Figure 1. Inhibitory effect of biomass extracts on gastrointestinal lipases activity. Biomass extracts of the strains isolated from the $10-20 \mathrm{~cm}$ superficial lakeshore soil (A), $<10 \mathrm{~cm}$ superficial lakeshore soil (B), lake sediment (C), and desert soil (D). Only those extracts in which residual activity obtained was less than $50 \%$ for one or both enzymes are shown. *Biomass extracts that showed less than $35 \%$ of residual activity on both enzymes. Biomass was obtained from Gly-SM superficial cultures after 7 days of growth. Residual activity was measured using PHIBLA with an emulsion of TG(4:0).

Figure 2. Photographs of strains selected as best producers of inhibitors in glycerol-soymilk agar culture medium.

Figure 3. Phylogenetic tree for bacteria strains producing lipase inhibitors by neighbor joining analysis based on their 16S rRNA gene sequences. Numbers at the nodes are bootstrap values (of 1,000 replicates).

Figure 4. Dose-response curves of the organic extracts of the strains AC104-10 (Streptomyces cinereoruber), AC104-6 (not identified.), and AC3-4 (Nocardia yamanashiensis). Panel A, effect on rHPL; Panel B, effect on RGL. The enzyme was pre-incubated with the inhibitor for $1 \mathrm{~h}$ in the presence of $4 \mathrm{mmol} \mathrm{l}^{-1}$ NaTDC. Residual activity was measured using PHIBLA with an emulsion of TG(4:0) as substrate. 
329 Table 1. Identification of isolated strains capable of producing gastrointestinal lipase inhibitors.

\begin{tabular}{|c|c|c|c|c|}
\hline $\mathbf{N}^{\circ}$ & Origin & Identification & $\begin{array}{c}\text { Identity } \\
(\%)\end{array}$ & $\begin{array}{c}\text { Accession } \\
\text { number }\end{array}$ \\
\hline AC104-3 & Lakeshore, $10-20 \mathrm{~cm}$ superficial soil & Amycolatopsis balhimycina & 99 & NR 025564.1 \\
\hline AC104-5 & Lakeshore, $10-20 \mathrm{~cm}$ superficial soil & Streptomyces longwoodensis & 99 & NR 041161.1 \\
\hline AC104-6 & Lakeshore, $10-20 \mathrm{~cm}$ superficial soil & $N D$ & ND & ND \\
\hline AC104-7 & Lakeshore, $10-20 \mathrm{~cm}$ superficial soil & Streptomyces cyslabdanicus & 99 & NR 136867.1 \\
\hline AC104-10 & Lakeshore, $10-20 \mathrm{~cm}$ superficial soil & Streptomyces cinereoruber & 99 & NR 112261.1 \\
\hline AC104-18 & Lakeshore, $10-20 \mathrm{~cm}$ superficial soil & Streptomyces gardneri & 99 & NR 112575.1 \\
\hline AC104-20 & Lakeshore, $10-20 \mathrm{~cm}$ superficial soil & $N D$ & ND & ND \\
\hline AC104-21 & Lakeshore, $10-20 \mathrm{~cm}$ superficial soil & Streptomyces resistomycificus & 99 & NR 112287.1 \\
\hline ACS102-2 & Lakeshore, $10-20 \mathrm{~cm}$ superficial soil & Streptomyces polyantibioticus & 99 & NR 043573.1 \\
\hline ACS102-12 & Lakeshore, $10-20 \mathrm{~cm}$ superficial soil & Streptomyces vinaceus & 100 & NR 041131.1 \\
\hline AC3-1 & Lakeshore, $<10 \mathrm{~cm}$ superficial soil & Streptomyces resistomycificus & 99 & NR 112287.1 \\
\hline AC3-3 & Lakeshore, $<10 \mathrm{~cm}$ superficial soil & Streptomyces resistomycificus & 99 & NR 112287.1 \\
\hline $\mathrm{AC} 3-4$ & Lakeshore, $<10 \mathrm{~cm}$ superficial soil & Nocardia yamanashiensis & 99 & NR 024803.1 \\
\hline $\mathrm{AC} 3-5$ & Lakeshore, $<10 \mathrm{~cm}$ superficial soil & Streptomyces chartreusis & 99 & NR 114825.1 \\
\hline AC3-8 & Lakeshore, $<10 \mathrm{~cm}$ superficial soil & Streptomyces longwoodensis & 98 & NR 041161.1 \\
\hline AC3-9 & Lakeshore, $<10 \mathrm{~cm}$ superficial soil & Streptomyces spororaveus & 99 & NR 112469.1 \\
\hline AC3-11 & Lakeshore, $<10 \mathrm{~cm}$ superficial soil & Streptomyces ederensis & 99 & NR 112457.1 \\
\hline AC3-12 & Lakeshore, $<10 \mathrm{~cm}$ superficial soil & Streptomyces rishiriensis & 99 & NR 044141.1 \\
\hline AC5-2 & Lakeshore, $<10 \mathrm{~cm}$ superficial soil & Streptomyces griseorubiginosus & 99 & NR 112350.1 \\
\hline AC5-7 & Lakeshore, $<10 \mathrm{~cm}$ superficial soil & Streptomyces chartreusis & 99 & NR 114825.1 \\
\hline ACS1-1 & Lakeshore, $<10 \mathrm{~cm}$ superficial soil & Streptomyces alboniger & 99 & NR 043228.2 \\
\hline ACPLRF-1 & Lake sediment & Bacillus tequilensis & 99 & NR 104919.1 \\
\hline ACPLRF-2 & Lake sediment & $N D$ & ND & ND \\
\hline ACSLRF-7 & Lake sediment & Streptomyces albogriseolus & 99 & NR 112487.1 \\
\hline ACSLRF-9 & Lake sediment & Streptomyces californicus & 99 & NR 112257.1 \\
\hline ACSLRF-17 & Lake sediment & Streptomyces albogriseolus & 99 & NR 112487.1 \\
\hline ACSLRF-25 & Lake sediment & $N D$ & ND & ND \\
\hline ACSLRF-26 & Lake sediment & Streptomyces albogriseolus & 99 & NR 112487.1 \\
\hline ACSLRF-27 & Lake sediment & Actinomadura geliboluensis & 100 & NR 109059.1 \\
\hline A114 & Desert soil & Streptomyces regensis & 99 & NR 112402.1 \\
\hline A127 & Desert soil & Streptomyces mexicanus & 99 & NR 114647.1 \\
\hline A135 & Desert soil & Bacillus licheniformis & 100 & NR 118996.1 \\
\hline A147 & Desert soil & Bacillus subtilis subsp. Spizizenii & 100 & NR 118486.1 \\
\hline A62-A & Desert soil & Aureobasidium pullulans & 99 & JF439462.1 \\
\hline A95 & Desert soil & $N D$ & ND & ND \\
\hline A99-B & Desert soil & Streptomyces africanus & 99 & NR 112600.1 \\
\hline B11 & Desert soil & Aspergillus nidulans & 100 & KP278174.1 \\
\hline
\end{tabular}




\begin{tabular}{lllll} 
B36 & Desert soil & Ascomycota sp. & 96 & JN561255.1 \\
B58 & Desert soil & Aspergillus fruticulosus & 99 & AB248969.1 \\
B8 & Desert soil & ND & ND & ND \\
\hline
\end{tabular}

330 ND: Not determined because there were no coincidences of alignment with reported sequences. 
Figure 1.

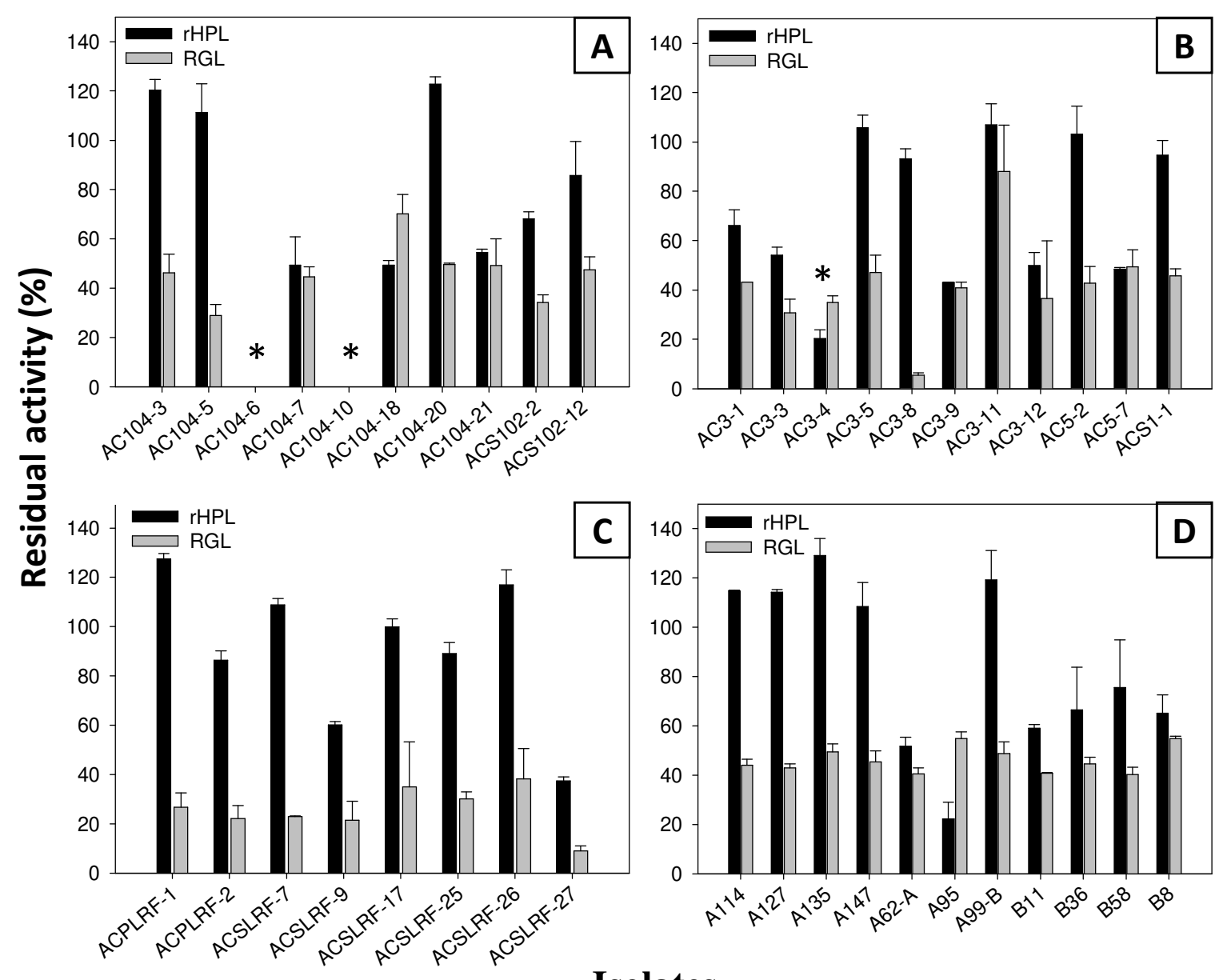

334

\section{Isolates}


Figure 2.

339

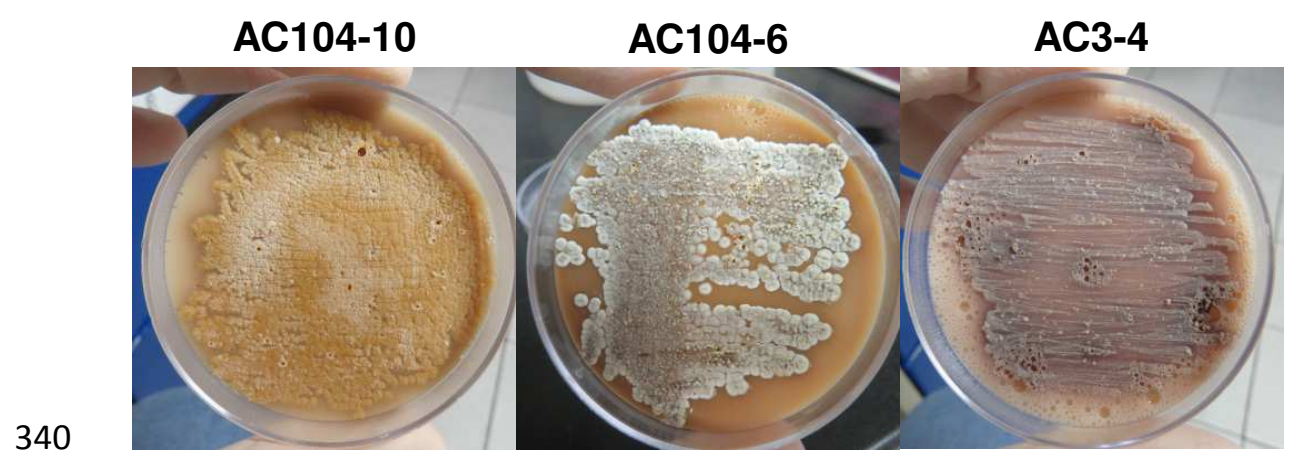




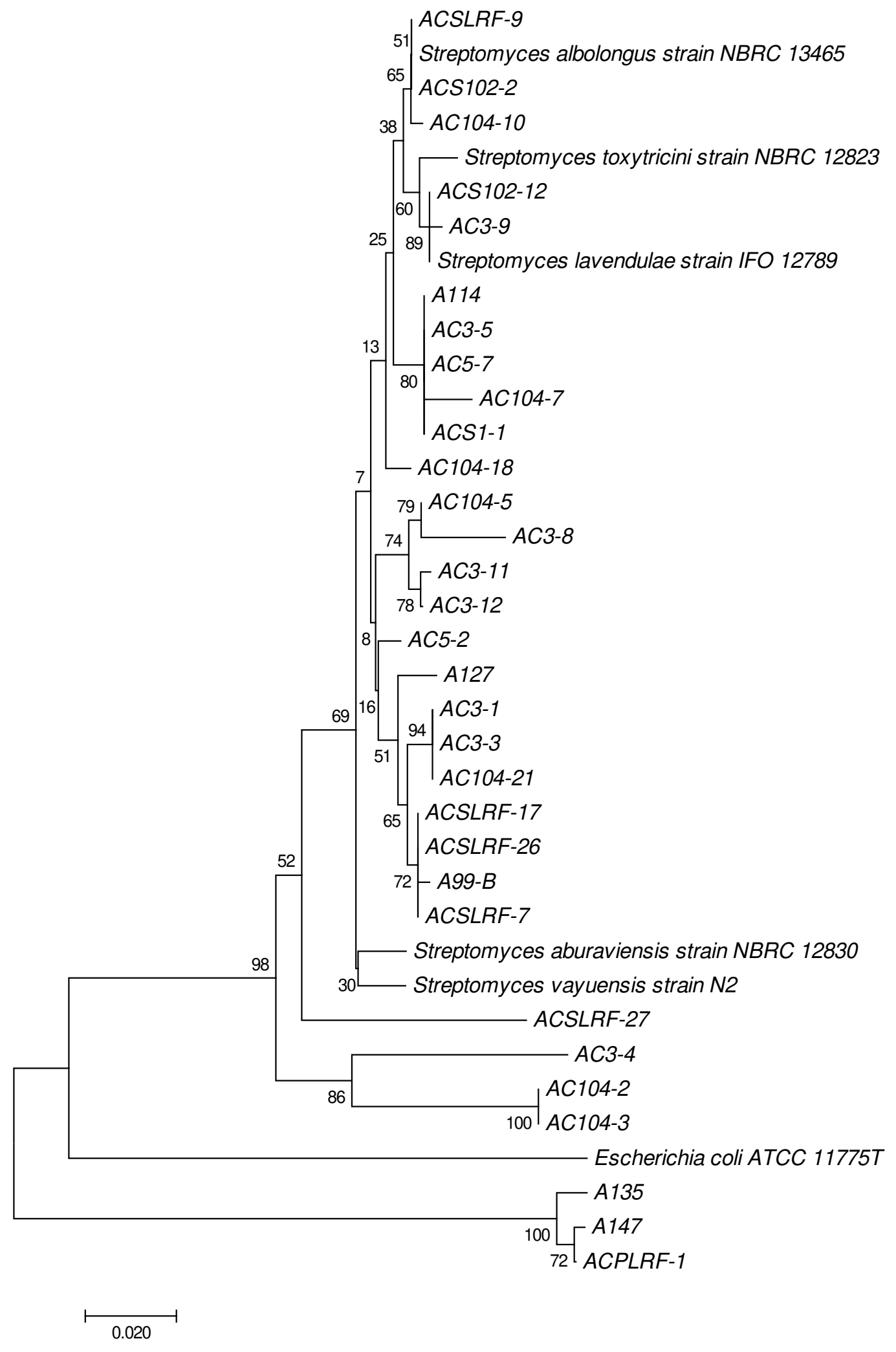




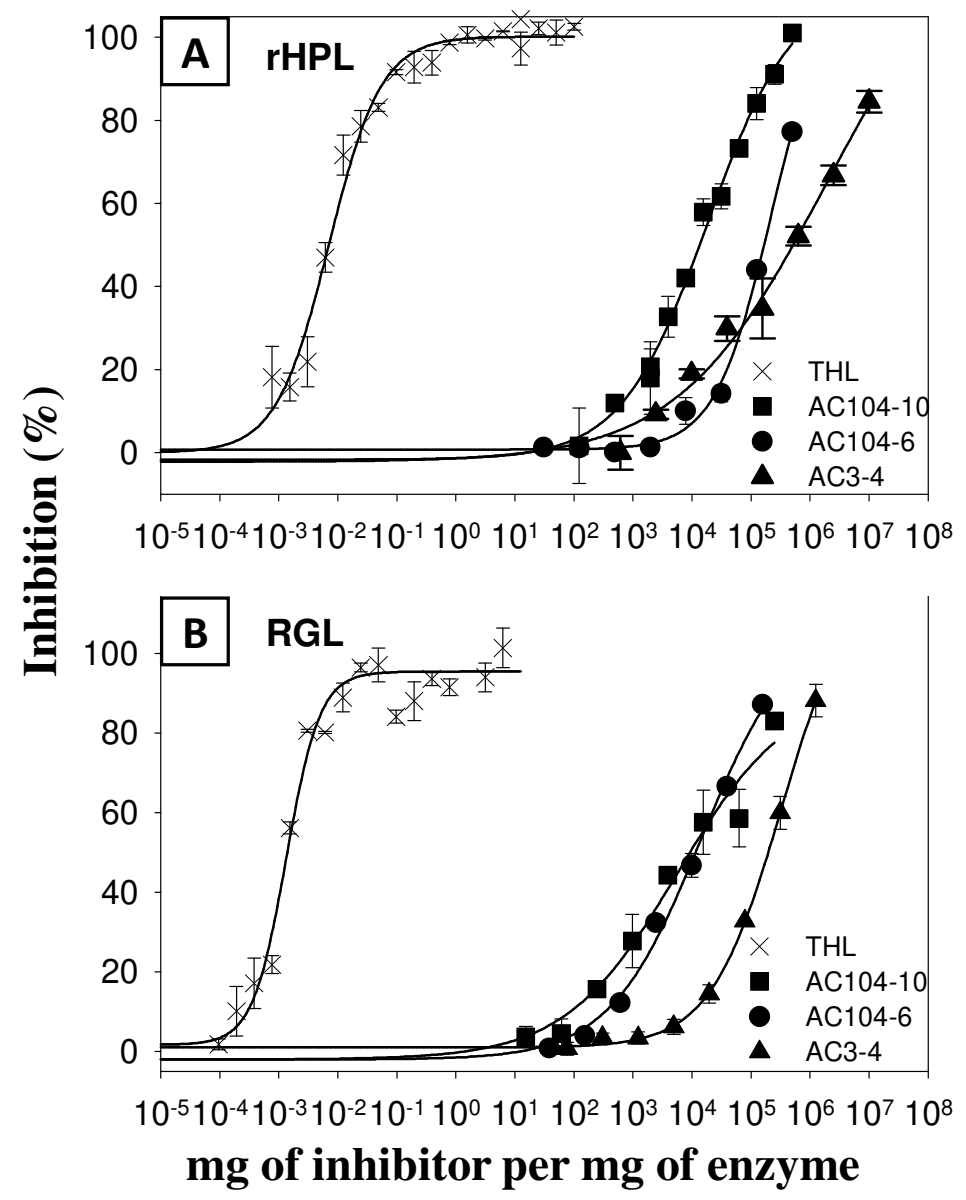

345 